\title{
Nogo-A antibodies enhance axonal repair and remyelination in neuro-inflammatory and demyelinating pathology
}

Ineichen, Benjamin V ; Kapitza, Sandra ; Bleul, Christiane ; Good, Nicolas ; Plattner, Patricia S ; Seyedsadr, Maryam S ; Kaiser, Julia ; Schneider, Marc P ; Zörner, Björn ; Martin, Roland ; Linnebank, Michael ; Schwab, Martin E

\begin{abstract}
Two hallmarks of chronic multiple sclerosis lesions are the absence of significant spontaneous remyelination and primary as well as secondary neurodegeneration. Both characteristics may be influenced by the presence of inhibitory factors preventing myelin and neuronal repair. We investigated the potential of antibodies against Nogo-A, a well-known inhibitory protein for neuronal growth and plasticity, to enhance neuronal regeneration and remyelination in two animal models of multiple sclerosis. We induced a targeted experimental autoimmune encephalomyelitis (EAE) lesion in the dorsal funiculus of the cervical spinal cord of adult rats resulting in a large drop of skilled forelimb motor functions. We subsequently observed improved recovery of forelimb function after anti-Nogo-A treatment. Anterograde tracing of the corticospinal tract revealed enhanced axonal sprouting and arborisation within the spinal cord gray matter preferentially targeting pre-motor and motor spinal cord laminae on lesion level and above in the anti-Nogo-A-treated animals. An important additional effect of Nogo-A-neutralization was enhanced remyelination observed after lysolecithin-induced demyelination of spinal tracts. Whereas remyelinated fiber numbers in the lesion site were increased several fold, no effect of Nogo-A-inhibition was observed on oligodendrocyte precursor proliferation, migration, or differentiation. Enhancing remyelination and promoting axonal regeneration and plasticity represent important unmet medical needs in multiple sclerosis. Anti-Nogo-A antibodies hold promise as a potential new therapy for multiple sclerosis, in particular during the chronic phase of the disease when neurodegeneration and remyelination failure determine disability evolution.
\end{abstract}

DOI: https://doi.org/10.1007/s00401-017-1745-3

Posted at the Zurich Open Repository and Archive, University of Zurich ZORA URL: https://doi.org/10.5167/uzh-139486

Journal Article

Accepted Version

Originally published at:

Ineichen, Benjamin V; Kapitza, Sandra; Bleul, Christiane; Good, Nicolas; Plattner, Patricia S; Seyedsadr, Maryam S; Kaiser, Julia; Schneider, Marc P; Zörner, Björn; Martin, Roland; Linnebank, Michael; Schwab, Martin E (2017). Nogo-A antibodies enhance axonal repair and remyelination in neuro-inflammatory and demyelinating pathology. Acta Neuropathologica, 134(3):423-440.

DOI: https://doi.org/10.1007/s00401-017-1745-3 


\section{Nogo-A-antibodies for progressive multiple sclerosis}

Benjamin V. Ineichen ${ }^{1 *}$, Patricia S. Plattner ${ }^{1 *}$, Nicolas Good ${ }^{1}$, Roland Martin ${ }^{2}$, Michael Linnebank ${ }^{2 \#}$, Martin E. Schwab ${ }^{1}$

${ }^{1}$ Brain Research Institute, University of Zurich and Department of Health Sciences and Technology, ETH Zurich, 8057 Zurich, Switzerland

${ }^{2}$ Dept. of Neurology, University Hospital Zurich, 8091 Zurich, Switzerland

${ }^{\#}$ Current address: Clinic of Neurology, Helios Klinik Hagen-Ambrock, Germany

*These authors contributed equally and share the first authorship

\section{Corresponding authors}

Prof. Martin E. Schwab: schwab@hifo.uzh.ch

Dr. med. Benjamin V. Ineichen: ineichen@protonmail.ch

\section{Key points}

Solid pre-clinical data suggests Nogo-A-neutralization as a potential therapeutic approach for neuroinflammatory and demyelinating pathology. Nogo-A-antibodies are now in early clinical development for multiple sclerosis (MS). Their potential to boost axonal regeneration and compensatory fiber growth as well as myelin repair makes them an attractive candidate to treat also progressive MS in which neurodegeneration and chronic demyelination are hallmarks. 


\begin{abstract}
Most of the current therapies as well as many of the clinical trials for Multiple Sclerosis (MS) target the inflammatory autoimmune processes, but less than $20 \%$ of all clinical trials investigate potential therapies for the chronic progressive disease stage of MS. The latter is responsible for the steadily increasing disability in many patients, and there is an urgent need for novel therapies that protect nervous system tissue and enhance axonal growth and/or remyelination. As outlined in this review, solid pre-clinical data suggest neutralization of the neurite outgrowth inhibitor Nogo-A as a potential new way to achieve both, axonal and myelin repair. Several phase I clinical studies with anti-Nogo-A antibodies have been conducted in different disease paradigms including MS and spinal cord injury. Data from spinal cord injury and amyotrophic lateral sclerosis (ALS) trials accredit a good safety profile of high doses of anti-Nogo-A-antibodies intravenously or intrathecally. An antibody against a Nogo receptor subunit, LINGO-1, was recently shown to improve outcome in acute optic neuritis in a phase II study. Nogo-A suppressing antibodies could be novel drug candidates for the relapsing as well as the progressive MS disease stage. In this review, we summarize the available pre-clinical and clinical evidence on Nogo-A and elucidate its potential use as a therapy for progressive MS.
\end{abstract}




\section{Introduction}

Multiple sclerosis (MS) is the leading cause of non-traumatic neurological disability in young adults in Europe and America [1]. It is an inflammatory demyelinating disease of the central nervous system (CNS) [2]. The causes of MS are not yet fully understood, but a complex genetic trait and several environmental risk factors have been identified, and the prevailing view suggests an autoimmune etiology [3].

In $85 \%$ of cases, the disease begins with a relapsing remitting course (RRMS), during which bouts of inflammatory disease activity with transient blood brain-barrier (BBB) opening are observed. In most patients, RRMS is followed by a progressive phase. This phase is defined by a disappearance of relapses and a gradually increase in disability without remission; finally, many patients become wheelchair bound. This form is referred to as secondary progressive MS (SPMS). In $10 \%$ of cases, patients suffer from a primary progressive disease course with no superimposed neuro-inflammatory bouts, referred to as primary progressive MS (PPMS) [4]. Thus, approximately $95 \%$ of patients are affected by extensive neurodegeneration sooner or later in the disease course.

However, no therapies are currently available that simultaneously dampen the inflammatory reactions and also protect the axons from degeneration [5]. Over the last 20 years, several compounds have been well-established in the treatment regimen of MS patients: interferon beta, glatiramer acetate, teriflunomide, dimethyl fumarate, natalizumab, fingolimod, alemtuzumab and mitoxantrone [6]. All of these have mainly immunomodulatory or immunosuppressive properties and are therefore more effective for the treatment of early MS disease stages where acute inflammation is predominant $[7,8]$. Although interferon beta and mitoxantrone were investigated in progressive MS, final conclusions about their effectiveness in treating this chronic disease stage are still unclear and the effect is at best moderate $[9,10]$. Another compound was approved in 2016: daclizumab, a humanized IgG against interleukin-2 receptor alpha chain on $T$ cells $[11,12]$. Ocrelizumab, a humanized anti-CD20 IgG $[13,14]$, is at the edge to clinical approval. Ocrelizumab is notably the first treatment option for PPMS (reviewed in [15]).

This is a breakthrough, in particular with regard to disappointing trials during the last 25 years assessing the effectiveness of drug candidates in progressive MS stages [16]. Important reasons for failure of these trials include that they only targeted the adaptive immune mechanisms. Besides that, the design of these studies was not suited to identify effects in patients suffering from progressive MS [17]. The difficulties in testing potential therapies for progressive MS are as well reflected by the fact that only a small amount of all current clinical MS trials investigates interventions for the progressive stage. This is shown by a systematic search on clinicaltrials.gov detecting as few as $17.3 \%$ of all studies investigating such interventions (126 of 727 studies, search string: "Multiple Sclerosis OR MS", last search date: $01^{\text {st }}$ of March, 2016). A further complication at the preclinical level is that no proper animal model is available for progressive MS [18]. However, many lessons were learned from preclinical [18] and clinical trials [16]. Additionally, promising new drug candidates are currently in development (reviewed in [19]).

One such candidate, which is in early clinical development for progressive (and relapsing) MS, is an antibody against the protein Nogo-A. In this review, we give a brief overview on this myelinassociated, nerve fiber growth inhibitory protein and its receptors and we summarize its relation to demyelinating, neuro-inflammatory and neurodegenerative pathology from clinical and preclinical evidence. 


\section{Multiple sclerosis leads to extensive neurodegeneration}

\subsection{The pathogenic cascade leading to neurodegeneration}

Axonal and neuronal injury is a common phenomenon in acute, relapsing MS lesions as shown by histological analysis of MS tissue [20,21], MRI [22] and magnetic resonance spectroscopy [23]. The prevailing view is that infiltration of immune cells and subsequent demyelination are responsible for this axonal loss [24].

The early pathological processes trigger a cascade of events which often lead to chronic demyelination and neurodegeneration [25], the hallmarks of the secondary progressive disease stage. The chronic inflammation results in microglia and macrophage activation producing reactive oxygen and nitrogen species (ROS/NOS) which can lead to mitochondrial damage $[26,27]$ (reviewed in [28]), metabolic stress, protein misfolding and deceased axonal transport [29, 30]. Accumulating evidence suggests genuine hypoxia as another mechanism contributing to the tissue injury in acute as well as chronic MS lesions [31-33].

\subsection{Chronic demyelination amplifies neurodegeneration}

The demyelinated tissue often fails to successfully repair the myelin leading to chronically denuded axons $[34,35]$. This is in part due to failure of oligodendrocyte precursor differentiation and myelination [35]. This chronic demyelination can lead to a lack of support function from the oligodendrocytes/myelin sheaths which ultimately results in axonal decline $[36,37]$. Ion channel redistribution is yet another sequel of chronic demyelination: different neuronal ion channels show redistribution along axons to compensate ionic imbalance, e.g. voltage-gated sodium channels (Nav1.2 and Nav1.6) [38], acid-sensing ion channel 1 (ASIC1) [39, 40], and transient receptor potential cation channel subfamily M member 4 (TRPM4) [41] (reviewed in [42]). This channel redistribution results in ionic imbalance further perpetuating tissue damage [42].

All above-mentioned destructive processes can be amplified by pre-existing brain injuries and factors associated with brain-ageing [25]. Resulting lesions show slow expansion leading to general CNS tissue atrophy [43]. This can result in extensive axonal injury which can be as high as $70 \%$ of axons being destroyed in chronic white matter lesions of severely disabled MS patients [44, 45]. In fact, the progressive neuronal degeneration closely correlates with the progressive neurological decline [46].

\subsection{Therapeutic opportunities}

This cascade of pathogenic events culminating in extensive axonal decline offers therapeutic opportunities. One of them is the enhancement of neuronal plasticity and regeneration of neurons and axons. The promotion of remyelination by recruitment of the oligodendrocyte precursor pool is yet another one. Important for therapeutic approaches is that successful remyelination was shown to stop the progressive axonal loss [47, 48].

\section{The Nogo-A protein: its distribution and receptors}

One of the drug candidates in early clinical development which would be able to induce axonal regeneration and remyelination is an antibody against the neurite outgrowth inhibitory protein Nogo-A [49]. The Nogo-A protein was first characterized as an inhibitory protein for neurite outgrowth in brain and spinal cord myelin in vitro in 1988 [50]; its cDNA was cloned in 2000 [51, 52]. It downregulates neuronal growth, stabilizes the CNS wiring and restricts plasticity in the adult CNS [53]. Nogo-A is a member of the reticulon family and is highly conserved across species. Three isoforms are generated by alternative splicing; A, B and C, but only Nogo-A has been shown to have 
inhibitory effects in the CNS. Nogo-A is present in various cell types of the CNS, including oligodendrocytes and neurons [54]. It is localized at the cell surface and in the endoplasmatic reticulum (ER) and can have different membrane topologies with regard to a cytoplasmic versus extracellular position of the $\mathrm{N}$ terminus [55].

Two inhibitory regions have been identified in this 1200 amino acid long protein, Nogo-A- $\Delta 20$ (amino acids 544-725 in rat Nogo-A) and Nogo-66 (amino acids 1055-1079 in rat Nogo-A, links the two long hydrophobic stretches which span the cell membrane) [49]. The Nogo receptor 1 (NgR1) has been described as a receptor for Nogo-66 [56]. Upon Nogo-A-binding, NgR1 associates with the transmembrane proteins leucine rich repeat and Immunoglobin-like domain-containing protein 1 (LINGO-1) and p75 or tumour necrosis factor- $\alpha$ (TNF $\alpha$ ) receptor superfamily member 19 (TROY) to form a multisubunit receptor complex $[49,57]$. The sphingosine-1-phosphate receptor 2 (S1PR2) is a receptor for Nogo-A- $\Delta 20$ [58] (Fig. 1a).

Although Nogo-66 and Nogo-A- $\Delta 20$ bind to distinct receptors, it was demonstrated that they modulate the same intracellular signaling pathway: ras homolog gene family member $A(R h o A)$ and rho-associated protein kinase (ROCK) [57] (Fig. 1d). The intracellular changes induced by the signaling cascade include reduced growth of actin filaments, collapse of the growth cone, destabilization of microtubules, and downregulation of growth genes in the neuronal cell body [57, 59]. Paired Immunoglobulin-like receptor B (PirB) is an alternative receptor for Nogo-66. This receptor is expressed in many parts of the CNS at low levels but its relevance for signaling might be restricted to neural development or after ischemia [60].

LINGO-1 is a co-receptor for NgR1 upon Nogo-A binding (Fig. 1a). It is expressed exclusively on oligodendrocytes and neurons and it is upregulated upon CNS injury across various animal models and human CNS diseases [61]. Antagonization of LINGO-1 has been shown to be beneficial in various animal models in terms of axonal regeneration and remyelination [61]. However, as LINGO-1 is distributed more widely in the CNS than NgR1 [62], other ligands might exist besides Nogo-A and NgR1. Comparison of the effects of LINGO-1 neutralization to those of Nogo-A neutralization is therefore of great interest (Table 1). Moreover, Nogo-A, like LINGO-1, is largely expressed in the CNS representing a mostly CNS-specific drug target.

Besides Nogo-A, the myelin proteins myelin-associated glycoprotein (MAG) and oligodendrocytemyelin glycoprotein (OMgp) are also ligands for NgR1 and were also reported to have neurite growth inhibitory activity in vitro. Not much is known about their in vivo functions in the context of neurite growth [63]. Nogo-A is by far the best studied one, and its extensive characterization suggests an important role during different neurodegenerative disorders $[64,65]$.

\section{Nogo-A is an inhibitor of nerve fiber growth and regeneration}

In neuronal development, Nogo-A acts as a regulator of axonal growth, branching and fasciculation [66]. It also regulates the internode length and Ranvier node formation during myelin formation [67].Nogo-A is involved in the termination of the critical plastic period in several regions of the postnatal CNS $[49,53]$. In the adult CNS, Nogo-A takes part in the stabilization of the structure and wiring of the CNS by restricting neurite growth to short distances. However, this growth restricting function of Nogo-A also inhibits regenerative and longer-range plastic events following injury or disease [53]. Suppressing the actions of Nogo-A by different means enhances plasticity and axonal regeneration, e.g. in rodent and monkey models of spinal cord injury and stroke; genetic Nogo- 
deletion, Nogo-neutralizing antibodies, auto-immunization with Nogo-A, a blocking Nogo receptor fusion protein or a Nogo receptor blocking peptide have been used in these animal models (reviewed in [53]).

Throughout these studies, Nogo-A-neutralization enhanced regrowth and compensatory sprouting of functionally important fiber systems such as the corticospinal tract as well as anatomical plasticity on different levels. At the same time, animals consistently showed significant functional recovery, e.g. in locomotion, skilled stepping over irregular ladders, balance or fine forepaw movements during grasping [53]. These beneficial effects appeared within $2-4$ weeks after the treatment and, at least in spinal cord injury, seemed to be more efficient in acute settings [68]. However, blocking Nogo-A with NgR1-Fc fusion protein enhanced anatomical and functional recovery also when administered several months after spinal cord trauma [69]. In stroke, even treatment in chronic stages after large ischemic cortical strokes led to improved functional recovery and increased axonal sprouting [70]. Furthermore, the antibody treatment also had positive effects on stroke recovery in aged rats [71].

Of note, transient pharmacogenetic blockade of the newly grown midline-crossing corticospinal fibers after stroke abrogated the recovered grasping function [72]. This shows that newly grown fibers are indeed responsible for improved recovery after anti-Nogo-A antibody treatment. Especially important regarding future human use of these antibodies are the observations that neurological adverse effects like enhanced pain, spasticity or epileptic attacks have never been observed in these studies [73]. Several antibodies with different epitope specificities for the rat and human Nogo-A have been used in preclinical and clinical research. Table 2 summarizes these antibodies, their epitopes, and types.

Another function of Nogo-A, potentially contributing to its ability to enhance recovery from CNS injury is its involvement in synaptic plasticity. These processes are mainly dependent on neuronal Nogo-A. Dendritic as well as synaptic spine architecture was shown to be influenced by Nogo-A and NgR1 signaling in the hippocampus [74]. Long term potentiation of hippocampal and cortical synapses was increased when Nogo-A or NgR1 were inactivated [75-77]. Furthermore, genetic deletion of the Nogo receptor family NgR1, NgR2, and NgR3 revealed an important role of Nogo-A as a brake on synapse formation in development [78].

\section{The role of Nogo-A in neuro-inflammatory and demyelinating conditions}

In recent years, the idea has been presented that Nogo-A may play a regulatory role in animal models of neuroinflammatory diseases and may thus be considered a potential therapeutic target for MS. Its abundant presence in myelin and myelin debris around acute and chronic MS lesions could restrict axonal regrowth as well as efficient myelin repair (Fig. 1). This hypothesis is supported by a considerable amount of studies from different laboratories using different animal models of MS and strategies for Nogo-A-neutralization. Moreover, there are supportive data on Nogo-A in MS patients. For a comprehensive molecular review on Nogo-A and MS, see Lee and Petratos [79].

Pioneering work by Karnezis and colleagues showed an important role of Nogo-A in the mouse model of autoimmune inflammatory CNS disease experimental autoimmune encephalomyelitis (EAE) [80]. They suppressed Nogo-A either by vaccination against Nogo-A or gene deletion. They found lower clinical scores and slower disease progression as well as reduced histological inflammation, demyelination and axonal damage. The reduced axonal pathology correlated well with the reduction 
in the severity of clinical disability and EAE progression. At the immunological level, vaccination with Nogo-A induced a shift in the production from pro-inflammatory Th1 to anti-inflammatory Th2 cells. The latter observation has not been reproduced so far, however.

The immune response to vaccination of EAE susceptible mice with Nogo-A peptides, representing different epitopes of the extracellular Nogo-A domain Nogo-66, revealed that some epitopes were encephalitogenic while others ameliorated established EAE [81]. These effects appeared to be mediated by Nogo-66-specific T cells.

Fontoura and colleagues [82] found that intravenous application of anti-Nogo-A IgG after EAE induction with MOG led to the prevention of disease onset for up to 12 days after the treatment was stopped. Compared to PBS or control IgG injections, the anti-Nogo-A IgG treatment decreased the incidence and severity of EAE and also blocked the progression of the disease.

Blocking Nogo-A by means of neutralizing antibodies has also been shown to enhance recovery in established neuro-inflammation [83]: An improved clinical as well as anatomical outcome, i.e. reduced levels of axonal degeneration shown with the marker P-CRMP-2, was shown after therapeutic administration of anti-Nogo-A antibodies during the course of EAE in mice.

Better clinical outcome in EAE was also observed by using a different way of Nogo-A suppression, namely by genetic knock down with small interfering RNA (siRNA) [84]. In vitro and in vivo, Nogo-A knock down led to higher levels of the growth-associated protein 43 (GAP43) in neurons [85]. This indicates that axonal repair was enhanced by suppressing Nogo-A. Interestingly, using this geneknock-out approach, the proliferation and cytokine production of myelin-specific $T$ cells were unaltered suggesting that enhanced axonal regeneration could be the mechanism for the improved clinical recovery. This could be in line with observations in spinal cord injury and stroke models in which Nogo-A-suppression led to enhanced fiber growth and plasticity. Axonal regeneration could, at least in part, be responsible for functional recovery at an early MS disease stage, e.g. in the remission phases [86]. These plastic compensatory strategies of the CNS, e.g. by sprouting of surviving axons, formation of compensatory circuits or recruitment of reserve pathways, have been shown in animal models of stroke [72], spinal cord injury [87], as well as neuro-inflammatory pathology [88].

Interestingly, Nogo-A mRNA and protein levels were observed to be inversely correlated with those of the axonal growth marker GAP43 at different stages of the course of EAE [89]. This work showed that Nogo-A mRNA expression is reduced at preclinical and acute phases, which is followed by upregulation of mRNA and protein during the chronic EAE stage. In contrast, GAP43 was upregulated during acute EAE and downregulated in chronic EAE, often in close spatial proximity to Nogo-A mRNA/protein. The reduction of Nogo-A expression within an active inflammatory lesion therefore could facilitate axonal sprouting, whereas the higher levels of Nogo-A in the chronic lesions could impede neurite growth.

The pre-clinical assessment of potential therapies for progressive MS is hampered by the fact that no animal models are available for mimicking the progressive MS disease course [18]. Most models fail to reproduce the complexity of the processes which define progressive MS, e.g. widespread microglia activation, chronic oxidative injury, subpial demyelination and cortical pathology at the same time [18]. Moreover, some models that claim to present a progressive phenotype, e.g. immunizing Biozzi $\mathrm{ABH}$ mice with spinal cord homogenate and complete Freund's adjuvant [90], reflect stable disease on a high level of disability rather than true progression. 
Chronic demyelination is an important hallmark of progressive MS. Therefore, toxin-induced demyelination models are increasingly used to define therapies aiming at enhancing remyelination, e.g. lysolecithin, ethidium bromide, or cuprizone [91]. Results from such studies suggest that Nogo-A may also be involved in myelin repair in addition to possible immune modulatory and regenerationenhancing effects. Studies on myelin development in vitro and in vivo [67] showed that, by acting as a repulsive cue, Nogo-A influences and regulates the periodic, non-overlapping arrangement of myelin internodes along axons as well as their number and internodal distances [67]. By genetically deleting Nogo-A in oligodendrocytes, the relevance of this hypothesis was tested in vivo in spinal lysolecithin-induced demyelinating lesions. Interestingly, Nogo-A-deficient mice showed enhanced myelin repair compared to control mice. The amount of myelinating oligodendrocytes was unchanged within the demyelinated lesion. This strongly supports the hypothesis of an increased myelinogenic potential of the Nogo-A deficient oligodendrocytes, i.e. Nogo-A-deficient oligodendrocytes can form more myelin internodes around axons. Therefore, the neutralization of Nogo-A by antibodies can potentially be exploited to enhance remyelination. The involvement of Nogo-A and its receptors during myelin formation is supported by several other developmental in vitro and in vivo studies [92-94].

In a clinically relevant approach using antibody mediated Nogo-A-neutralization, subsequent to lysolecithin lesions in adult rat spinal cords, our lab obtained evidence for enhanced myelin repair as a consequence of this treatment (unpublished observations). Of note, the antibody mediated neutralization of LINGO-1, a component of the NgR1-Nogo-A receptor complex, also led to enhanced oligodendrocyte precursor cell differentiation during primary myelination as well as during myelin repair in different in vivo MS animal models [95-97]. In contrast, over-expression of LINGO-1 impeded this precursor differentiation and abolishing myelin repair [98]. These (re-)myelination promoting effects are potentially also mediated by RhoA downstream signaling [95], but other signaling cascades were as well shown to be involved [98] (Table 1).

The potential of antibodies directed against myelin antigens to promote remyelination has already been shown (reviewed in [99]). Murine as well as human anti-myelin antibodies were able to boost remyelination in rodent MS models. The proposed mechanisms were either involving removal of myelin debris after injury or direct effects on oligodendrocyte precursor cells.

\section{The role of Nogo-A in multiple sclerosis}

In addition to these preclinical studies, Nogo-A has also been examined in MS. Nogo-A was found to be upregulated in surviving oligodendrocytes in chronic active demyelinating lesions of MS patients [100]. This is consistent with findings in EAE mice [89]. Elevated serum and cerebrospinal fluid (CSF) autoantibody levels against the large N-terminal domain of Nogo-A have been found in blood samples from MS patients [101], but anti-Nogo-A antibodies exist also in healthy controls. The levels of these antibodies were reported to be increased in RRMS patients compared to chronic-progressive MS patients. Additionally, these anti-Nogo antibodies were more frequent in younger MS patients compared to older ones [101]. The role(s) of these Nogo-A-antibodies is currently unclear; they could reflect the ongoing auto-inflammatory processes against myelin including Nogo-A. Whether some of these antibodies could participate in reparative functions myelin or axons remains to be determined.

\section{Nogo-A-antibodies in clinical trials}

The experimental data from studies using different MS animal models and the exploratory data from MS patients which have been summarized above suggest Nogo-A-antibodies as a potential 
therapeutic agent for the treatment of RRMS and/or progressive forms of MS. Two phase 1 studies for Nogo-A-antibodies were recently conducted in patients with RRMS (ClinicalTrials.gov, NCT01424423 and NCT01435993). Both studies, with a very limited number of patients, have been terminated, but their results are not fully published yet. In its online clinical study register, GlaxoSmithKline states that the reasons for termination were unrelated to safety issues of the antibody treatment.

Two phase 1 studies to assess acute safety, tolerability and pharmacokinetics of anti-Nogo-A antibodies were successfully completed in two other CNS diseases: one after intrathecal administration of anti-Nogo-A antibodies over 30 days in patients with acute spinal cord injury (NCT00406016; Kucher et al., in preparation), and another trial using very high doses of intravenously infused antibodies in patients with amyotrophic lateral sclerosis (ALS, NCT00875446) [102]. Both of these trials showed excellent safety and tolerance of the Nogo-A-antibody treatment. A phase 2 study including more than 300 patients with ALS who were randomised to either anti-Nogo-A antibodies or placebo further showed that there was no apparent imbalance between treatment groups in adverse events (NCT01753076). Placebo-controlled multicentric phase 2 proof-of-principle studies are currently in preparation for spinal cord injury.

An antibody against a Nogo-66 receptor associated component, LINGO-1 (opicinumab), has been tested in phase 1 and 2 studies in patients with RR-/progressive MS or with optic neuritis. High doses of i.v. antibodies were well tolerated [103] . In a phase 2 study in acute optic neuritis patients treated with anti-LINGO-1, vision did not improve after 8 months, but the velocity of nerve conduction, as measured by visually evoked potentials (VEP), was up to $41 \%$ less reduced compared to placebo treatment [104]. Since the latency of the VEP primarily reflects intact myelin sheaths, these data are interpreted as a sign of preserved myelin sheaths or remyelination. The failure to meet the secondary outcome of attenuation of the loss of retinal nerve fibers by optical coherence tomography indicates that retinal neurons and/or axons were lost despite of the anti-LINGO-1 treatment. However, these interpretations are preliminary and await further confirmation.

A very recent press release from a phase 2 study using monthly i.v. anti-LINGO-1 for relapsing and progressive MS did not meet its primary endpoint, a multicomponent analysis evaluating motor and cognitive function as well as disability (http://media.biogen.com/press-release/investorrelations/biogen-reports-top-line-results-phase-2-study-opicinumab-anti-lingo). The opicinumab infusions were combined with a concurrent interferon beta add-on therapy. A potential reason for this failure despite promising pre-clinical results could be the ambitious and complex trial design. It used a complex multicomponent readout as primary endpoint including the Timed 25-Foot Walk (T25FW), the 9-Hole Peg Test (9HPT), and the Expanded Disability Status Scale (EDSS). The latter two tests have received criticism for being insensitive outcome measures for progressive MS trials [16]. EDSS is an ordinal scale, therefore, the statistical comparison between contiguous scores is insensitive. Moreover, scores can show high differences between different raters [105]. The 9HPT has floor and ceiling effects limiting its use for progressive MS trials. The patient collective was also very heterogeneous consisting of RRMS and SPMS patients further complicating final interpretations of the preliminary published study results. Full study results including subgroup analysis of RRMS vs. SPMS patients will be available in the next few months and will bring further clarification. 


\section{Clinical aspects of a Nogo-A-antibody therapy}

\subsection{Requirements for novel MS therapies}

As summarized above, a number of trials to achieve a therapeutic effect in progressive MS are currently ongoing. Experience from previous trials points to different requirements which need to be fulfilled by new therapies [25]: first, on-going or new inflammatory activity needs to be blocked, and, if possible, the compartmentalized intra-CNS chronic activation of microglia should be inhibited as well. Second, neuro- and/or myelin protection should be achieved to inhibit the above mentioned mechanisms that contribute to neuronal decline in the progressive disease stage. Third, given the presumable intrathecal compartmentalization of inflammation in the progressive stage, a potential drug needs to reach the CNS tissue in spite of a mostly intact BBB [25, 106], e.g. by intrathecal application [107], or delivery into the CSF space via a shuttle system. Intrathecal application leads to locally maximized drug concentrations with low systemic exposure and can therefore be expected to have minimal systemic side effects [107]. Fourth, besides immunomodulation and neuro-/myelin protection, the regenerative effects of treatments like anti-Nogo-A should foster repair as much as possible in this phase of disease. Fifth, the different pathogenic mechanisms in the progressive disease may require combinatorial therapies tackling the different targets of the degenerative process as well as various repair processes like axonal sprouting and myelin repair [16]. Sixth, and critical for testing the effects of such single or combination therapies, the most informative patient subgroups should be identified, and suitable trial designs including imaging readouts and biomarkers for degeneration and repair need to be applied.

Under these assumptions, neutralization of Nogo-A seems a feasible and promising therapeutic strategy for the progressive disease stage of MS. As summarized above, a number of pre-clinical studies, mainly in the rodent EAE and lysolecithin model, and different ways of inhibiting Nogo-A showed functional as well as anatomical recovery in terms of axonal sparing, sprouting and myelin repair $[67,80,83,84]$. One study also showed a beneficial immunomodulatory function of Nogo-Ainhibition shifting the cytokine profile of T cells from a pro- to an anti-inflammatory one [80]. An antiNogo-A therapy could therefore tackle two or even three of the major pathogenic hallmarks of MS (Fig. 1b, c, and e). NgR1/Lingo-1 inhibition has also been proposed as an approach to abolish Nogo-Asignaling in MS [79]. Disappointing results of clinical trials investigating growth factors such as BDNF, NGF, CNTF, PDGF, or GDNF suggest that targets should be tissue- and cell type-specific. None of the other MS drugs, either still in development or already clinically approved, have CNS-specific targets. Therefore, both Nogo-A-antibodies and LINGO-1-antibodies are promising agents due to their high CNS target-specificity. In addition, it seems plausible that Nogo-A is present in the myelin debris in MS plaques prior to macrophage clearance thereby limiting the potential of these plaques for axonal repair. This myelin debris-associated Nogo-A could in fact be an important target of the Nogo-Aantibodies to achieve axonal repair in MS. Moreover, the engulfment of myelin debris, potentially ameliorated through opsonization by Nogo-A-antibodies, could enhance remyelination [79].

\subsection{Pharmacological aspects of Nogo-A-antibody therapy}

Perhaps the greatest concern of the Nogo-A-antibody therapy is its potential limited access to the CNS through the BBB, especially in progressive MS in which the disease process is compartmentalized behind a mainly intact BBB [25].

Preclinical data from a rat stroke model in our laboratory revealed that about $0.1 \%$ of a blood infused anti-Nogo-A antibody reached the CSF 7 days after i.v. bolus infusion (unpublished observations). 
This is consistent with trials in mouse EAE using an IgG [108] and in naïve rats using an anti-LINGO-1IgG [109].

Data from clinical trials support this notion. A study investigating the CSF concentration of rituximab after i.v. application in two MS patients (one with progressive disease) revealed $0.1-0.25 \%$ of this antibody being present in the CSF 24 weeks after application [110]. More evidence comes from clinical trials with LINGO-1-IgG [111] and rHIgM22 antibody [112]. Data from a pharmacokinetic study with rHIgM22 show that it was found in the brain of 14/14 patients after 2 days and in 5/12 patients after 29 days following intravenous infusion of a single dose. This IgM antibody is 5 times larger than IgG such as the LINGO-1- or Nogo-A-antibody. In the phase 1 study with i.v. anti-LINGO-1 in 72 healthy volunteers or in 47 patients with either relapsing or progressive MS, doses of $\geq 10 \mathrm{mg} / \mathrm{kg}$ resulted in CSF concentrations of this antibody which were associated with $90 \%$ of the maximum remyelination effect in rat remyelination studies [103]. It seems therefore plausible that sufficient amounts of antibodies can cross the BBB when very high i.v. doses are administered.

\subsection{Potential "Off-target" effects of Nogo-A-antibodies}

Both, animal models and human observations have linked Nogo-A and NgR1 to schizophrenia (reviewed in [113]). Genetic association studies have identified Nogo-A and NgR as risk polymorphisms for neuropsychiatric disorders such as schizophrenia [114]. Besides this, mice lacking Nogo-A or NgR1 demonstrate behavioral phenotypes reflecting aspects of schizophrenia, e.g. deficits in prepulse inhibition (PPI) $[115,116]$. Neurodevelopmental mechanisms seem to be responsible for this. In line with this, schizophrenic phenotypes have never been observed in rodents $[115,117]$ or primates [73] during or after therapeutic Nogo-A-antibody application.

Nogo-A restricts neuronal plasticity and fiber growth in the adult CNS. Inhibition of this protein by antibodies could therefore potentially lead to aberrant fiber growth and wiring causing e.g. chronic pain or dyskinesia. These pathologies were, however, not observed in the trials for ALS [102] and spinal cord injury (NCT00406016; Kucher et al., in preparation) or in adult spinal cord injured rats [68] or primates [73] under Nogo-A-antibody therapy.

\section{Conclusions}

Axonal degeneration and chronic demyelination are hallmarks of chronic, slowly progressing MS. Preclinical studies in rodent EAE models showed that suppression of the growth inhibitory CNS protein Nogo-A, e.g. by neutralizing anti-Nogo-A-antibodies, enhance axonal sprouting and regeneration as well as the formation of new, functional circuits. Also myelin repair was enhanced after genetic deletion of Nogo-A in the lysolecithin myelin lesion model. Based on these data, antiNogo-A antibodies could be a promising new therapy for relapsing as well as progressive MS. Phase 1 and 2 studies with anti-Nogo-A-antibodies are currently under way for other neurological indications. The time seems ripe to test these antagonists of the Nogo-A - Nogo receptor pathway as novel therapeutic agents for relapsing and in particular progressive MS. 


\section{Tables}

Table 1 Differences between the Nogo-A-antibody and the LINGO-1-antibody.

\begin{tabular}{|c|c|c|}
\hline & Anti-Nogo-A-antibodies & Anti-LINGO-1-antibodies \\
\hline Target & Nogo-A & LINGO-1 \\
\hline Expression & $\begin{array}{l}\text { Neurons and oligodendrocytes, } \\
\text { oligodendrocyte precursor cells (OPCs) }\end{array}$ & $\begin{array}{l}\text { Neurons and oligodendrocytes, } \\
\text { OPCs }\end{array}$ \\
\hline Receptors for ligands & $\begin{array}{l}\text { Sphingosine-1-phosphate receptor } 2 \\
\text { (Nogo-A- } \Delta 20 \text { ), NgR1-LINGO-1-p75 } \\
\text { receptor complex (Nogo-66), Paired } \\
\text { Immunoglobulin-like receptor B (PirB) }\end{array}$ & $\begin{array}{l}\text { Nogo-A, oligodendrocyte-myelin } \\
\text { glycoprotein (together with p75 and } \\
\text { NgR1), other unknown ligands }\end{array}$ \\
\hline ream signaling & $\begin{array}{l}\text { Ras homolog gene family member A } \\
\text { (RhoA) }\end{array}$ & $\begin{array}{l}\text { RhoA, protein kinase } B(A k t) \text {, other } \\
\text { downstream signaling unknown }\end{array}$ \\
\hline $\begin{array}{lr}\text { Beneficial } & \text { effects in } \\
\text { pre-clinical } & \text { animal } \\
\text { models } & \end{array}$ & $\begin{array}{l}\text { Promoting axonal sprouting and } \\
\text { regeneration } \\
\text { Enhancing remyelination } \\
\text { Modulating immune response in } \\
\text { neuro-inflammation }\end{array}$ & $\begin{array}{l}\text { Enhancing remyelination by } \\
\text { improving } \quad \text { oligodendrocyte } \\
\text { differentiation. } \\
\text { Promoting axonal repair. }\end{array}$ \\
\hline $\begin{array}{l}\text { Other animal models in } \\
\text { which the therapy } \\
\text { showed beneficial } \\
\text { effects }\end{array}$ & $\begin{array}{l}\text { Stroke, spinal cord injury, traumatic } \\
\text { brain injury, optic nerve injury, } \\
\text { amyotrophic lateral sclerosis (ALS) }\end{array}$ & $\begin{array}{l}\text { Glaucoma, Parkinson's disease, } \\
\text { spinal cord injury }\end{array}$ \\
\hline $\begin{array}{l}\text { Presumable indication } \\
\text { spectrum in MS }\end{array}$ & Relapsing and progressive MS & Relapsing and progressive MS \\
\hline $\begin{array}{l}\text { Current clinical phase in } \\
\text { MS }\end{array}$ & Phase 1 & Phase 2 completed (optic neuritis) \\
\hline
\end{tabular}

Table 2 Target regions and antibody types of monoclonal Nogo-A-antibodies in preclinical and clinical research. The protein Nogo-A has two inhibitory domains, Nogo-A- $\Delta 20$ (amino acids 544-725 in rat Nogo-A) and Nogo-66 (amino acids 1055-1079 in rat Nogo-A, links the two long hydrophobic stretches which span the cell membrane).

\begin{tabular}{|l|l|l|l|}
\hline Antibody & Target amino acids of Nogo-A & Target region & Antibody type \\
\hline 11C7 [118] & $623-640$ (rat) & Nogo-A- $\Delta 20$ & Mouse IgG1 \\
\hline 11A8 [118] & $\sim 209-233$ (rat) & N-terminal extracellular part & Mouse IgG1 \\
\hline 3D11 [118] & $\sim 910-920$ (rat) & N-terminal extracellular part & Mouse IgG1 \\
\hline 7B12 [118] & $\sim 763-820$ (rat) & N-terminal extracellular part & Mouse IgG1 \\
\hline IN1 [119] & Not specified & - & Mouse IgM \\
\hline $\begin{array}{l}\text { ATI-355 } \\
\text { (NCT00406016) }\end{array}$ & $345-354$ (human) & N-terminal extracellular part & Human IgG4 \\
\hline $\begin{array}{l}\text { Ozanezumab } \\
\text { [102] }\end{array}$ & $610-621$ (human) & Nogo-A- $\Delta 20$ & Humanized IgG1 \\
\hline
\end{tabular}




\section{Figure legends}

Fig. 1 Receptors and downstream signaling of Nogo-A and potential mechanism(s) of Nogo-Aantibody therapy in multiple sclerosis (MS).

(a) The myelin-associated protein Nogo-A has two inhibitory regions, Nogo-66 and Nogo-A- $\Delta 20$. Nogo-66 binds to Nogo-receptor 1 (NgR1) which forms a complex with LINGO-1, p75, and/or TROY. Sphingosine-1-phosphate receptor 2 (S1PR2) has recently been identified as a Nogo-A- $\Delta 20$ receptor [58].

(b) In acute MS lesions, the attack of the myelin sheath by immune cells leads to demyelination. The myelin-associated protein Nogo-A is then present in the myelin debris potentially limiting axonal/myelin repair in MS plaques.

(c) In acute and chronic MS lesions, neuronal/axonal degeneration can be very prominent. Nogo-A, present in the myelin debris and surrounding myelin sheaths, limits regeneration and compensatory sprouting of these damaged axons. Blocking Nogo-A with antibodies potentially leads to regeneration of axons and restoration of compensatory neuronal circuits.

(d) Signaling cascade upon binding of Nogo-A to its cognate receptors: neuronal S1PR2 as well as the NgR1-LINGO-1-p75/TROY receptor complex activates RhoA and RhoA-Associated Kinase (ROCK). Different downstream targets including the phosphorylation of collapsin response mediator protein 2 (CRMP-2) [83] lead to a disassembly of the actin and microtubule system with subsequent detrimental collapse of the growth cone.

(e) After demyelination, oligodendrocyte precursor cells are recruited and differentiate into oligodendrocytes to remyelinate the naked axon. As suggested by recent evidence [67], Nogo-A seems to limit the myelinogenic potential of oligodendrocytes: oligodendrocytes from Nogo-Adeficient mice can form an increased amount of myelin internodes. Nogo-A mediated repulsive interactions would lead to spatial segregation at Ranvier node formation. Remyelinated myelin sheaths are characteristically thinner than original myelin sheaths. 


\section{Acknowledgements}

We thank Dr. Roman Willi and Miguel Maurer for input and discussion about Nogo-A-antibody pharmacology. We are grateful for funding from the Swiss Multiple Sclerosis Society, the HartmannMüller-Foundation, the Swiss National Science Foundation and the Desirée-and-Niels-Yde Foundation.

\section{Compliance with Ethical Standards}

\section{Funding}

This work was supported by grants of the Swiss National Science Foundation (Grant Nr. 31003A149315-1 to MES), the Christopher and Dana Reeve Foundation (to MES), the Swiss MS Society, the Hartmann-Müller Foundation, Zurich, the Desirée-and-Niels-Yde Foundation (to BVI) and an MD-PhD fellowship of the Swiss National Science Foundation (No. 323530_151488, to BVI). No funding was received specifically for the publication of this article.

\section{Conflicts of interest}

MES is a founder and board member of the University of Zurich spin-off company NovaGo Therapeutics Inc., seeking to develop Nogo-A-antibody-based therapeutics. Benjamin V. Ineichen, Patricia S. Plattner, Nicolas Good, Roland Martin, and Michael Linnebank declare no conflict of interest. 


\section{References}

1. Organization WH. Multiple Sclerosis International Federation. Atlas: Multiple Sclerosis Resources in the World 2008. World Health Organization, Geneva, Switzerland. 2008:13-7.

2. Trapp BD, Nave KA. Multiple sclerosis: an immune or neurodegenerative disorder? Annual review of neuroscience. 2008;31:247-69.

3. Sawcer S, Hellenthal G, Pirinen M, Spencer CC, Patsopoulos NA, Moutsianas L, et al. Genetic risk and a primary role for cell-mediated immune mechanisms in multiple sclerosis. Nature. 2011 Aug 11;476(7359):2149.

4. Tallantyre EC, Bo L, Al-Rawashdeh O, Owens T, Polman CH, Lowe J, et al. Greater loss of axons in primary progressive multiple sclerosis plaques compared to secondary progressive disease. Brain : a journal of neurology. 2009 May;132(Pt 5):1190-9.

5. Fox RJ, Thompson A, Baker D, Baneke P, Brown D, Browne $P$, et al. Setting a research agenda for progressive multiple sclerosis: the International Collaborative on Progressive MS. Multiple sclerosis (Houndmills, Basingstoke, England). 2012 Nov;18(11):1534-40.

6. Torkildsen O, Myhr KM, Bo L. Disease-modifying treatments for multiple sclerosis - a review of approved medications. European journal of neurology. 2016 Jan;23 Suppl 1:18-27.

7. Coles AJ, Cox A, Le Page E, Jones J, Trip SA, Deans J, et al. The window of therapeutic opportunity in multiple sclerosis: evidence from monoclonal antibody therapy. Journal of neurology. 2006 Jan;253(1):98-108.

8. Hauser SL, Chan JR, Oksenberg JR. Multiple sclerosis: Prospects and promise. Annals of neurology. 2013 Sep;74(3):317-27.

9. Kappos L, Polman C, Pozzilli C, Thompson A, Beckmann K, Dahlke F. Final analysis of the European multicenter trial on IFNbeta-1b in secondary-progressive MS. Neurology. 2001 Dec 11;57(11):1969-75.

10. Hartung HP, Gonsette R, Konig N, Kwiecinski H, Guseo A, Morrissey SP, et al. Mitoxantrone in progressive multiple sclerosis: a placebo-controlled, double-blind, randomised, multicentre trial. Lancet (London, England). 2002 Dec 21-28;360(9350):2018-25.

11. Kappos L, Wiendl H, Selmaj K, Arnold DL, Havrdova E, Boyko A, et al. Daclizumab HYP versus Interferon Beta-1a in Relapsing Multiple Sclerosis. The New England journal of medicine. 2015 Oct 8;373(15):1418-28.

12. Gold R, Giovannoni G, Selmaj K, Havrdova E, Montalban X, Radue EW, et al. Daclizumab high-yield process in relapsing-remitting multiple sclerosis (SELECT): a randomised, double-blind, placebo-controlled trial. Lancet (London, England). 2013 Jun 22;381(9884):2167-75.

13. Montalban X, Hemmer B, Rammohan K, Giovannoni G, De Seze J, Bar-Or A, et al. Efficacy and Safety of Ocrelizumab in Primary Progressive Multiple Sclerosis: Results of the Phase III Double-Blind, Placebo-Controlled ORATORIO Study (S49. 001). Neurology. 2016;86(16 Supplement):S49. 001.

14. Hauser S, Comi G, Hartung H-P, Selmaj K, Traboulsee A, Bar-Or A, et al. Efficacy and safety of ocrelizumab in relapsing multiple sclerosis-results of the interferon-beta-1a-controlled, double-blind, Phase III OPERA I and II studies. MULTIPLE SCLEROSIS JOURNAL; 2015: SAGE PUBLICATIONS LTD 1 OLIVERS YARD, 55 CITY ROAD, LONDON EC1Y 1SP, ENGLAND; 2015. p. 61-2.

15. McGinley MP, Moss BP, Cohen JA. Safety of monoclonal antibodies for the treatment of multiple sclerosis. Expert opinion on drug safety. 2016 Oct 31:1-12.

16. Ontaneda D, Fox RJ, Chataway J. Clinical trials in progressive multiple sclerosis: lessons learned and future perspectives. The Lancet Neurology. 2015 Feb;14(2):208-23.

17. Ransohoff RM, Hafler DA, Lucchinetti CF. Multiple sclerosis-a quiet revolution. Nature reviews Neurology. 2015 Mar;11(3):134-42.

18. Lassmann H, Bradl M. Multiple sclerosis: experimental models and reality. Acta neuropathologica. 2016 Oct 20.

19. Shirani A, Okuda DT, Stuve O. Therapeutic Advances and Future Prospects in Progressive Forms of Multiple Sclerosis. Neurotherapeutics : the journal of the American Society for Experimental NeuroTherapeutics. 2016 Jan;13(1):58-69.

20. Trapp BD, Peterson J, Ransohoff RM, Rudick R, Mork S, Bo L. Axonal transection in the lesions of multiple sclerosis. The New England journal of medicine. 1998 Jan 29;338(5):278-85.

21. Stadelmann C. Multiple sclerosis as a neurodegenerative disease: pathology, mechanisms and therapeutic implications. Current opinion in neurology. 2011 Jun;24(3):224-9.

22. Weinshenker BG. The natural history of multiple sclerosis: update 1998. Seminars in neurology. 1998;18(3):301-7.

23. Filippi M, Rocca MA, De Stefano N, Enzinger C, Fisher E, Horsfield MA, et al. Magnetic resonance techniques in multiple sclerosis: the present and the future. Archives of neurology. 2011 Dec;68(12):1514-20.

24. Criste G, Trapp B, Dutta R. Axonal loss in multiple sclerosis: causes and mechanisms. Handbook of clinical neurology. 2014;122:101-13. 
25. Mahad DH, Trapp BD, Lassmann H. Pathological mechanisms in progressive multiple sclerosis. The Lancet Neurology. 2015 Feb;14(2):183-93.

26. Fischer MT, Sharma R, Lim JL, Haider L, Frischer JM, Drexhage J, et al. NADPH oxidase expression in active multiple sclerosis lesions in relation to oxidative tissue damage and mitochondrial injury. Brain : a journal of neurology. 2012 Mar;135(Pt 3):886-99.

27. Campbell GR, Kraytsberg Y, Krishnan KJ, Ohno N, Ziabreva I, Reeve A, et al. Clonally expanded mitochondrial DNA deletions within the choroid plexus in multiple sclerosis. Acta neuropathologica. 2012 Aug;124(2):209-20.

28. Witte ME, Mahad DJ, Lassmann $\mathrm{H}$, van Horssen J. Mitochondrial dysfunction contributes to neurodegeneration in multiple sclerosis. Trends in molecular medicine. 2014 Mar;20(3):179-87.

29. Dendrou CA, Fugger L, Friese MA. Immunopathology of multiple sclerosis. Nature reviews Immunology. 2015 Sep 15;15(9):545-58.

30. Sorbara CD, Wagner NE, Ladwig A, Nikic I, Merkler D, Kleele T, et al. Pervasive axonal transport deficits in multiple sclerosis models. Neuron. 2014 Dec 17;84(6):1183-90.

31. Davies AL, Desai RA, Bloomfield PS, Mclntosh PR, Chapple KJ, Linington C, et al. Neurological deficits caused by tissue hypoxia in neuroinflammatory disease. Annals of neurology. 2013 Dec;74(6):815-25.

32. Desai RA, Davies AL, Tachrount M, Kasti M, Laulund F, Golay X, et al. Cause and prevention of demyelination in a model multiple sclerosis lesion. Annals of neurology. $2016 \mathrm{Apr} ; 79(4): 591-604$.

33. Lassmann H. Demyelination and neurodegeneration in multiple sclerosis: The role of hypoxia. Annals of neurology. 2016 Apr;79(4):520-1.

34. Patani R, Balaratnam M, Vora A, Reynolds R. Remyelination can be extensive in multiple sclerosis despite a long disease course. Neuropathology and applied neurobiology. 2007 Jun;33(3):277-87.

35. Franklin RJ, Gallo V. The translational biology of remyelination: past, present, and future. Glia. 2014 Nov;62(11):1905-15.

36. Nave KA. Myelination and support of axonal integrity by glia. Nature. 2010 Nov 11;468(7321):244-52.

37. Franklin RJ, ffrench-Constant C, Edgar JM, Smith KJ. Neuroprotection and repair in multiple sclerosis. Nature reviews Neurology. 2012 Nov 5;8(11):624-34.

38. Craner MJ, Newcombe J, Black JA, Hartle C, Cuzner ML, Waxman SG. Molecular changes in neurons in multiple sclerosis: altered axonal expression of Nav1.2 and Nav1.6 sodium channels and $\mathrm{Na}+\mathrm{Ca} 2+$ exchanger. Proceedings of the National Academy of Sciences of the United States of America. 2004 May 25;101(21):816873.

39. Vergo S, Craner MJ, Etzensperger R, Attfield K, Friese MA, Newcombe J, et al. Acid-sensing ion channel 1 is involved in both axonal injury and demyelination in multiple sclerosis and its animal model. Brain : a journal of neurology. 2011 Feb;134(Pt 2):571-84.

40. Friese MA, Craner MJ, Etzensperger R, Vergo S, Wemmie JA, Welsh MJ, et al. Acid-sensing ion channel1 contributes to axonal degeneration in autoimmune inflammation of the central nervous system. Nature medicine. 2007 Dec;13(12):1483-9.

41. Schattling B, Steinbach K, Thies E, Kruse M, Menigoz A, Ufer F, et al. TRPM4 cation channel mediates axonal and neuronal degeneration in experimental autoimmune encephalomyelitis and multiple sclerosis. Nature medicine. 2012 Dec;18(12):1805-11.

42. Friese MA, Schattling B, Fugger L. Mechanisms of neurodegeneration and axonal dysfunction in multiple sclerosis. Nature reviews Neurology. 2014 Apr;10(4):225-38.

43. Frischer JM, Weigand SD, Guo Y, Kale N, Parisi JE, Pirko I, et al. Clinical and pathological insights into the dynamic nature of the white matter multiple sclerosis plaque. Annals of neurology. 2015 Nov; 78(5):710-21.

44. Mews I, Bergmann M, Bunkowski S, Gullotta F, Bruck W. Oligodendrocyte and axon pathology in clinically silent multiple sclerosis lesions. Multiple sclerosis (Houndmills, Basingstoke, England). 1998 Apr;4(2):55-62.

45. Bjartmar C, Kidd G, Mork S, Rudick R, Trapp BD. Neurological disability correlates with spinal cord axonal loss and reduced $\mathrm{N}$-acetyl aspartate in chronic multiple sclerosis patients. Annals of neurology. 2000 Dec;48(6):893-901.

46. Sospedra M, Martin R. Immunology of multiple sclerosis. Annual review of immunology. 2005;23:683747.

47. Dubois-Dalcq M, Ffrench-Constant C, Franklin RJ. Enhancing central nervous system remyelination in multiple sclerosis. Neuron. 2005 Oct 6;48(1):9-12.

48. Wootla B, Denic A, Watzlawik JO, Warrington AE, Rodriguez M. Antibody-Mediated Oligodendrocyte Remyelination Promotes Axon Health in Progressive Demyelinating Disease. 2015 Sep 26.

49. Schwab ME. Functions of Nogo proteins and their receptors in the nervous system. Nature reviews Neuroscience. 2010 Dec;11(12):799-811. 
50. Caroni P, Schwab ME. Antibody against myelin-associated inhibitor of neurite growth neutralizes nonpermissive substrate properties of CNS white matter. Neuron. 1988 Mar;1(1):85-96.

51. GrandPre T, Nakamura F, Vartanian T, Strittmatter SM. Identification of the Nogo inhibitor of axon regeneration as a Reticulon protein. Nature. 2000 Jan 27;403(6768):439-44.

52. Chen MS, Huber AB, van der Haar ME, Frank M, Schnell L, Spillmann AA, et al. Nogo-A is a myelinassociated neurite outgrowth inhibitor and an antigen for monoclonal antibody IN-1. Nature. 2000 Jan 27;403(6768):434-9.

53. Schwab ME, Strittmatter SM. Nogo limits neural plasticity and recovery from injury. Current opinion in neurobiology. 2014 Aug;27:53-60.

54. Huber AB, Weinmann O, Brosamle C, Oertle T, Schwab ME. Patterns of Nogo mRNA and protein expression in the developing and adult rat and after CNS lesions. The Journal of neuroscience : the official journal of the Society for Neuroscience. 2002 May 1;22(9):3553-67.

55. Dodd DA, Niederoest B, Bloechlinger S, Dupuis L, Loeffler JP, Schwab ME. Nogo-A, -B, and -C are found on the cell surface and interact together in many different cell types. The Journal of biological chemistry. 2005 Apr 1;280(13):12494-502.

56. Wang KC, Koprivica V, Kim JA, Sivasankaran R, Guo Y, Neve RL, et al. Oligodendrocyte-myelin glycoprotein is a Nogo receptor ligand that inhibits neurite outgrowth. Nature. 2002 Jun 27;417(6892):941-4.

57. Nash $M$, Pribiag $H$, Fournier AE, Jacobson $C$. Central nervous system regeneration inhibitors and their intracellular substrates. Molecular neurobiology. 2009 Dec;40(3):224-35.

58. Kempf A, Tews B, Arzt ME, Weinmann O, Obermair FJ, Pernet V, et al. The sphingolipid receptor S1PR2 is a receptor for Nogo-a repressing synaptic plasticity. PLoS biology. 2014 Jan;12(1):e1001763.

59. Montani L, Gerrits B, Gehrig P, Kempf A, Dimou L, Wollscheid B, et al. Neuronal Nogo-A modulates growth cone motility via Rho-GTP/LIMK1/cofilin in the unlesioned adult nervous system. The Journal of biological chemistry. 2009 Apr 17;284(16):10793-807.

60. Gou X, Zhang $Q, X u ~ N$, Deng B, Wang H, Xu L, et al. Spatio-temporal expression of paired immunoglobulin-like receptor- $B$ in the adult mouse brain after focal cerebral ischaemia. Brain injury. 2013;27(11):1311-5.

61. Mi S, Pepinsky RB, Cadavid D. Blocking LINGO-1 as a therapy to promote CNS repair: from concept to the clinic. CNS drugs. 2013 Jul;27(7):493-503.

62. Barrette B, Vallieres N, Dube M, Lacroix S. Expression profile of receptors for myelin-associated inhibitors of axonal regeneration in the intact and injured mouse central nervous system. Molecular and cellular neurosciences. 2007 Apr;34(4):519-38.

63. Fujita $Y$, Yamashita T. Axon growth inhibition by RhoA/ROCK in the central nervous system. Frontiers in neuroscience. 2014;8:338.

64. Teng FY, Tang BL. Why do Nogo/Nogo-66 receptor gene knockouts result in inferior regeneration compared to treatment with neutralizing agents? Journal of neurochemistry. 2005 Aug;94(4):865-74.

65. Lee JK, Geoffroy CG, Chan AF, Tolentino KE, Crawford MJ, Leal MA, et al. Assessing spinal axon regeneration and sprouting in Nogo-, MAG-, and OMgp-deficient mice. Neuron. 2010 Jun 10;66(5):663-70.

66. Schmandke A, Schmandke A, Schwab ME. Nogo-A: Multiple Roles in CNS Development, Maintenance, and Disease. The Neuroscientist : a review journal bringing neurobiology, neurology and psychiatry. 2014 Jan 8;20(4):372-86.

67. Chong SY, Rosenberg SS, Fancy SP, Zhao C, Shen YA, Hahn AT, et al. Neurite outgrowth inhibitor NogoA establishes spatial segregation and extent of oligodendrocyte myelination. Proceedings of the National Academy of Sciences of the United States of America. 2012 Jan 24;109(4):1299-304.

68. Gonzenbach RR, Zoerner B, Schnell L, Weinmann O, Mir AK, Schwab ME. Delayed anti-nogo-a antibody application after spinal cord injury shows progressive loss of responsiveness. Journal of neurotrauma. 2012 Feb 10;29(3):567-78.

69. Wang X, Duffy P, McGee AW, Hasan O, Gould G, Tu N, et al. Recovery from chronic spinal cord contusion after Nogo receptor intervention. Annals of neurology. 2011 Nov;70(5):805-21.

70. Tsai SY, Papadopoulos CM, Schwab ME, Kartje GL. Delayed anti-nogo-a therapy improves function after chronic stroke in adult rats. Stroke; a journal of cerebral circulation. 2011 Jan;42(1):186-90.

71. Markus TM, Tsai SY, Bollnow MR, Farrer RG, O'Brien TE, Kindler-Baumann DR, et al. Recovery and brain reorganization after stroke in adult and aged rats. Annals of neurology. 2005 Dec;58(6):950-3.

72. Wahl AS, Omlor W, Rubio JC, Chen JL, Zheng H, Schroter A, et al. Neuronal repair. Asynchronous therapy restores motor control by rewiring of the rat corticospinal tract after stroke. Science (New York, NY). 2014 Jun 13;344(6189):1250-5. 
73. Freund P, Schmidlin E, Wannier T, Bloch J, Mir A, Schwab ME, et al. Nogo-A-specific antibody treatment enhances sprouting and functional recovery after cervical lesion in adult primates. Nature medicine. $2006 \mathrm{Jul} ; 12$ (7):790-2.

74. Zagrebelsky M, Schweigreiter R, Bandtlow CE, Schwab ME, Korte M. Nogo-A stabilizes the architecture of hippocampal neurons. The Journal of neuroscience : the official journal of the Society for Neuroscience. 2010 Oct 6;30(40):13220-34.

75. Delekate A, Zagrebelsky M, Kramer S, Schwab ME, Korte M. NogoA restricts synaptic plasticity in the adult hippocampus on a fast time scale. Proceedings of the National Academy of Sciences of the United States of America. 2011 Feb 08;108(6):2569-74.

76. Mironova YA, Giger RJ. Where no synapses go: gatekeepers of circuit remodeling and synaptic strength. Trends in neurosciences. 2013 Jun;36(6):363-73.

77. Zemmar A, Weinmann O, Kellner Y, Yu X, Vicente R, Gullo M, et al. Neutralization of Nogo-A enhances synaptic plasticity in the rodent motor cortex and improves motor learning in vivo. The Journal of neuroscience : the official journal of the Society for Neuroscience. 2014 Jun 25;34(26):8685-98.

78. Wills ZP, Mandel-Brehm C, Mardinly AR, McCord AE, Giger RJ, Greenberg ME. The nogo receptor family restricts synapse number in the developing hippocampus. Neuron. 2012 Feb 9;73(3):466-81.

79. Lee JY, Petratos S. Multiple sclerosis: does Nogo play a role? The Neuroscientist : a review journal bringing neurobiology, neurology and psychiatry. 2013 Aug;19(4):394-408.

80. Karnezis T, Mandemakers W, McQualter JL, Zheng B, Ho PP, Jordan KA, et al. The neurite outgrowth inhibitor Nogo A is involved in autoimmune-mediated demyelination. Nature neuroscience. 2004 Jul;7(7):73644.

81. Fontoura P, Ho PP, DeVoss J, Zheng B, Lee BJ, Kidd BA, et al. Immunity to the extracellular domain of Nogo-A modulates experimental autoimmune encephalomyelitis. Journal of immunology (Baltimore, Md : 1950). 2004 Dec 1;173(11):6981-92.

82. Fontoura P, Steinman L. Nogo in multiple sclerosis: growing roles of a growth inhibitor. Journal of the neurological sciences. 2006 Jun 15;245(1-2):201-10.

83. Petratos S, Ozturk E, Azari MF, Kenny R, Lee JY, Magee KA, et al. Limiting multiple sclerosis related axonopathy by blocking Nogo receptor and CRMP-2 phosphorylation. Brain : a journal of neurology. 2012 Jun;135(Pt 6):1794-818.

84. Yang $\mathrm{Y}$, Liu $\mathrm{Y}$, Wei $\mathrm{P}$, Peng $\mathrm{H}$, Winger R, Hussain RZ, et al. Silencing Nogo-A promotes functional recovery in demyelinating disease. Annals of neurology. $2010 \mathrm{Apr}$;67(4):498-507.

85. Nikic I, Merkler D, Sorbara C, Brinkoetter M, Kreutzfeldt M, Bareyre FM, et al. A reversible form of axon damage in experimental autoimmune encephalomyelitis and multiple sclerosis. Nature medicine. 2011 Apr;17(4):495-9.

86. Tomassini V, d'Ambrosio A, Petsas N, Wise RG, Sbardella E, Allen M, et al. The effect of inflammation and its reduction on brain plasticity in multiple sclerosis: MRI evidence. Human brain mapping. 2016 Jul;37(7):2431-45.

87. Bareyre FM, Kerschensteiner M, Raineteau O, Mettenleiter TC, Weinmann O, Schwab ME. The injured spinal cord spontaneously forms a new intraspinal circuit in adult rats. Nature neuroscience. 2004 Mar;7(3):269-77.

88. Kerschensteiner M, Bareyre FM, Buddeberg BS, Merkler D, Stadelmann C, Bruck W, et al. Remodeling of axonal connections contributes to recovery in an animal model of multiple sclerosis. The Journal of experimental medicine. 2004 Oct 18;200(8):1027-38.

89. Theotokis P, Lourbopoulos A, Touloumi O, Lagoudaki R, Kofidou E, Nousiopoulou E, et al. Time course and spatial profile of Nogo-A expression in experimental autoimmune encephalomyelitis in C57BL/6 mice. Journal of neuropathology and experimental neurology. 2012 Oct;71(10):907-20.

90. Anderson JM, Hampton DW, Patani R, Pryce G, Crowther RA, Reynolds R, et al. Abnormally phosphorylated tau is associated with neuronal and axonal loss in experimental autoimmune encephalomyelitis and multiple sclerosis. Brain : a journal of neurology. 2008 Jul;131(Pt 7):1736-48.

91. Denic A, Johnson AJ, Bieber AJ, Warrington AE, Rodriguez M, Pirko I. The relevance of animal models in multiple sclerosis research. Pathophysiology : the official journal of the International Society for Pathophysiology / ISP. 2011 Feb;18(1):21-9.

92. Jaillard C, Harrison S, Stankoff B, Aigrot MS, Calver AR, Duddy G, et al. Edg8/S1P5: an oligodendroglial receptor with dual function on process retraction and cell survival. The Journal of neuroscience : the official journal of the Society for Neuroscience. 2005 Feb 9;25(6):1459-69.

93. Pernet V, Joly S, Christ F, Dimou L, Schwab ME. Nogo-A and myelin-associated glycoprotein differently regulate oligodendrocyte maturation and myelin formation. The Journal of neuroscience : the official journal of the Society for Neuroscience. 2008 Jul 16;28(29):7435-44. 
94. Syed YA, Baer AS, Lubec G, Hoeger H, Widhalm G, Kotter MR. Inhibition of oligodendrocyte precursor cell differentiation by myelin-associated proteins. Neurosurgical focus. 2008;24(3-4):E5.

95. Mi S, Miller RH, Lee X, Scott ML, Shulag-Morskaya S, Shao Z, et al. LINGO-1 negatively regulates myelination by oligodendrocytes. Nature neuroscience. 2005 Jun;8(6):745-51.

96. Mi S, Hu B, Hahm K, Luo Y, Kam Hui ES, Yuan Q, et al. LINGO-1 antagonist promotes spinal cord remyelination and axonal integrity in MOG-induced experimental autoimmune encephalomyelitis. Nature medicine. 2007 Oct;13(10):1228-33.

97. Mi S, Miller RH, Tang W, Lee X, Hu B, Wu W, et al. Promotion of central nervous system remyelination by induced differentiation of oligodendrocyte precursor cells. Annals of neurology. 2009 Mar;65(3):304-15.

98. Lee X, Yang Z, Shao Z, Rosenberg SS, Levesque M, Pepinsky RB, et al. NGF regulates the expression of axonal LINGO-1 to inhibit oligodendrocyte differentiation and myelination. The Journal of neuroscience : the official journal of the Society for Neuroscience. 2007 Jan 3;27(1):220-5.

99. Wootla B, Watzlawik JO, Warrington AE, Wittenberg NJ, Denic A, Xu X, et al. Naturally Occurring Monoclonal Antibodies and Their Therapeutic Potential for Neurologic Diseases. JAMA neurology. 2015 Nov 1;72(11):1346-53.

100. Satoh J, Onoue H, Arima K, Yamamura T. Nogo-A and nogo receptor expression in demyelinating lesions of multiple sclerosis. Journal of neuropathology and experimental neurology. 2005 Feb;64(2):129-38.

101. Reindl M, Khantane S, Ehling R, Schanda K, Lutterotti A, Brinkhoff C, et al. Serum and cerebrospinal fluid antibodies to Nogo-A in patients with multiple sclerosis and acute neurological disorders. Journal of neuroimmunology. 2003 Dec;145(1-2):139-47.

102. Meininger V, Pradat PF, Corse A, Al-Sarraj S, Rix Brooks B, Caress JB, et al. Safety, pharmacokinetic, and functional effects of the nogo-a monoclonal antibody in amyotrophic lateral sclerosis: a randomized, first-inhuman clinical trial. PloS one. 2014;9(5):e97803.

103. Tran JQ, Rana J, Barkhof F, Melamed I, Gevorkyan H, Wattjes MP, et al. Randomized phase I trials of the safety/tolerability of anti-LINGO-1 monoclonal antibody BIIB033. Neurology-Neuroimmunology Neuroinflammation. 2014;1(2):e18.

104. Cadavid D, Balcer L, Galetta S, Aktas O, Ziemssen T, Vanopdenbosch L, et al. Evidence of remyelination with the anti-LINGO-1 monoclonal antibody BIIB033 after acute optic neuritis. Neurology; 2015: LIPPINCOTT WILLIAMS \& WILKINS TWO COMMERCE SQ, 2001 MARKET ST, PHILADELPHIA, PA 19103 USA; 2015. p. E46-E.

105. Noseworthy JH, Vandervoort MK, Wong CJ, Ebers GC. Interrater variability with the Expanded Disability Status Scale (EDSS) and Functional Systems (FS) in a multiple sclerosis clinical trial. The Canadian Cooperation MS Study Group. Neurology. 1990 Jun;40(6):971-5.

106. di Nuzzo L, Orlando R, Nasca C, Nicoletti F. Molecular pharmacodynamics of new oral drugs used in the treatment of multiple sclerosis. Drug design, development and therapy. 2014;8:555-68.

107. Bonnan M, Ferrari S, Bertandeau E, Demasles S, Krim E, Miquel M, et al. Intrathecal rituximab therapy in multiple sclerosis: review of evidence supporting the need for future trials. Current drug targets. 2014;15(13):1205-14.

108. Bien-Ly N, Boswell CA, Jeet S, Beach TG, Hoyte K, Luk W, et al. Lack of Widespread BBB Disruption in Alzheimer's Disease Models: Focus on Therapeutic Antibodies. Neuron. 2015 Oct 21;88(2):289-97.

109. Pepinsky RB, Shao Z, Ji B, Wang Q, Meng G, Walus L, et al. Exposure levels of anti-LINGO-1 Li81 antibody in the central nervous system and dose-efficacy relationships in rat spinal cord remyelination models after systemic administration. The Journal of pharmacology and experimental therapeutics. 2011 Nov;339(2):519-29.

110. Petereit HF, Rubbert-Roth A. Rituximab levels in cerebrospinal fluid of patients with neurological autoimmune disorders. Multiple sclerosis (Houndmills, Basingstoke, England). 2009 Feb;15(2):189-92.

111. Tran J, Palaparthy R, Zhao J, Brosofsky K, Ray S, Rana J, et al. Safety, tolerability and pharmacokinetics of the Anti-LINGO-1 Monoclonal antibody BIIB033 in healthy volunteers and subjects with multiple sclerosis (P02. 021). Neurology. 2012;78(Meeting Abstracts 1):P02. 021.

112. Greenberg BM, Rodriguez M, Kantarci O, Arnold D, Wang L, Carrazana E, et al. Safety and tolerability of the remyelinating therapeutic antibody rHIgM22 in patients with stable multiple sclerosis. Neurology; 2015: LIPPINCOTT WILLIAMS \& WILKINS TWO COMMERCE SQ, 2001 MARKET ST, PHILADELPHIA, PA 19103 USA; 2015. p. E48-E9.

113. Willi R, Schwab ME. Nogo and Nogo receptor: relevance to schizophrenia? Neurobiology of disease. 2013 Jun;54:150-7.

114. Lewis CM, Levinson DF, Wise LH, DeLisi LE, Straub RE, Hovatta I, et al. Genome scan meta-analysis of schizophrenia and bipolar disorder, part II: Schizophrenia. American journal of human genetics. 2003 Jul;73(1):34-48. 
115. Willi R, Weinmann O, Winter C, Klein J, Sohr R, Schnell L, et al. Constitutive genetic deletion of the growth regulator Nogo-A induces schizophrenia-related endophenotypes. The Journal of neuroscience : the official journal of the Society for Neuroscience. 2010 Jan 13;30(2):556-67.

116. Budel S, Padukkavidana T, Liu BP, Feng Z, Hu F, Johnson S, et al. Genetic variants of Nogo-66 receptor with possible association to schizophrenia block myelin inhibition of axon growth. The Journal of neuroscience : the official journal of the Society for Neuroscience. 2008 Dec 03;28(49):13161-72.

117. Craveiro LM, Weinmann O, Roschitzki B, Gonzenbach RR, Zorner B, Montani L, et al. Infusion of antiNogo-A antibodies in adult rats increases growth and synapse related proteins in the absence of behavioral alterations. Experimental neurology. 2013 Dec;250:52-68.

118. Oertle T, van der Haar ME, Bandtlow CE, Robeva A, Burfeind P, Buss A, et al. Nogo-A inhibits neurite outgrowth and cell spreading with three discrete regions. The Journal of neuroscience : the official journal of the Society for Neuroscience. 2003 Jul 2;23(13):5393-406.

119. Schnell L, Schwab ME. Axonal regeneration in the rat spinal cord produced by an antibody against myelin-associated neurite growth inhibitors. Nature. 1990 Jan 18;343(6255):269-72. 